\title{
Introduction to Case Study Special Issue-- Case Studies in Japan: Two Methods, Two Worldviews, Part 2
}

\author{
SHIGERU IWAKABE ${ }^{\mathrm{a}, \mathrm{b}}$
}

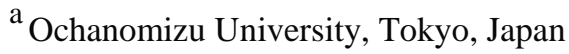 \\ ${ }^{\mathrm{b}}$ Correspondence regarding this article should be addressed to Shigeru Iwakabe, Graduate School of Humanities \\ and Sciences, Ochanomizu University, 2-1-1 Otsuka, Bunkyo-ku, Tokyo, 112-8610 \\ Email: iwakabe.shigeru@ocha.ac.jp \\ Acknowledgements. Many thanks to Sarah Iwakabe for extensive translation; to Kaori Nakamura for rigorous \\ editorial work; to Wakako Yamazaki, Ayumi Noda, and Yasuna Takabatake for their contribution in earlier versions \\ of translation; and finally to Dan Fishman for continued support throughout this project.
}

\begin{abstract}
The goal of this special issue is to present two dramatically different models of case studies, to compare their methodological features, and to explore potential ways to integrate the two to make best use of their respective strengths. The two case study articles present an opportunity to view the breadth of psychotherapy case studies and psychotherapy practice in Japan. The commentaries provided by four eminent psychologists from both in and outside Japan, and the subsequent responses from the two main authors, produce rich and stimulating dialogue that provides a forum for learning through case studies. This dialogue also helps to delineate the features of each case study. Reflecting on the two case study articles and the four commentaries, as the action editor of this special issue I offer my own observations, focusing on methodological issues of case studies and also on issues associated with differing cultural practices.
\end{abstract}

Key words: interventions; case study research methodology; dialogue through case studies; culture; evidential role and educational role of case studies

\section{BACKGROUND}

This issue of PCSP is devoted to commentaries and responses to them on two cases that were presented in the June issue of PCSP. Here is the introduction to the original series:

Japan is one of the main centers today in the use of case studies for the practice, research, and training of psychotherapy. To place this work in rich historical, social, cultural, epistemological, and clinical context, this issue of PCSP begins with a wide-ranging introduction by the accomplished Japanese psychologist, Shigeru Iwakabe, who is also the Action Editor of this issue.

To capture some of the depth and span of Japanese case studies, Iwakabe's introduction is followed by two notable examples. Together these case studies illustrate the ends of a methodological continuum, with a case by Kayoko Murase representing the traditional, 
Case Studies in Japan: Two Methods, Two Worldviews, Part 2

S. I wakabe

Pragmatic Case Studies in Psychotherapy, http://pcsp.libraries.rutgers.edu

Volume 11, Module 4, Article 1, pp. 230-238, 12-31-15 [copyright by author]

subjectively and narratively focused case study; and a case by Takashi Muto and Takashi Mitamura representing a scientifically precise single case design to objectively track in quantitative detail the change in targeted symptoms.

One area in which Japanese case studies have generally not focused is on the creation of standards to ensure an approach that is both systematic and of high methodological quality. The two case studies presented have been developed to encourage such standards by embodying them and by acting as models of how case studies can be presented. Also, in line with PCSP's usual approach and towards the goal of creating standards, together with a broader discussion of the nature and role of psychotherapy case studies in Japan, a future issue of PCSP will present commentaries on each case by prominent clinical psychologists, both non-Japanese and Japanese. Responses to these respective commentaries by each of the two original authors will follow.

In order to reach both Japanese-speaking and English-speaking readers, this issue of PCSP presents both English and Japanese versions of the articles (Editor's Note on the PCSP home page of the original series, 6-12-15).

Here are the three articles and links to them, in English and Japanese:

\section{PCSP Vol 11, No. 2 (2015). Table of Contents in English}

Introduction to Case Study Special Issue-- Case Studies in Japan: Two Methods, Two Worldviews

*** Shigeru Iwakabe

http://dx. doi.org/10.14713/pcsp.v11i2.1902

The Art of Communication Through Drawing: The Case of "Mr. R," a Young Man Professing Misanthropy While Longing for Connection With Others

*** Kayoko Murase http://dx.doi.org/10.14713/pcsp.v11i2.1903

Acceptance and Commitment Therapy for "Taro," a Japanese Client with Chronic Depression: A Replicated Treatment-Evaluation

*** Takashi Muto \& Takashi Mitamura

http://dx.doi.org/10.14713/pcsp.v11i2.1904

\section{PCSP Vol 11, No. 2 (2015). Table of Contents in Japanese}

事例研究特集号一はじめに日本における事例研究 : 2つの方法，2つの世界観

Iwakabe 岩壁 茂

http://dx.doi.org/10.14713/pcsp.v11i2.1906

描画を通したコミュニケーション：人間不信を標榜しながらも，他者とのつながりを 希求する青年 R 氏の事例 
Case Studies in Japan: Two Methods, Two Worldviews, Part 2

S. I wakabe

Pragmatic Case Studies in Psychotherapy, http://pcsp.libraries.rutgers.edu

Volume 11, Module 4, Article 1, pp. 230-238, 12-31-15 [copyright by author]

Murase 村瀬 嘉代子

http://dx.doi.org/10.14713/pcsp.v11i2.1907

慢性化したうつを抱えた日本人クライエント「太郎」に対するアクセプタンス\&コミ ットメント・セラピー：トリートメント評価による再現可能性検証

Muto 武藤 崇, Mitamura 三田村 仰

http://dx.doi.org/10.14713/pcsp.v11i2.1908

This issue of PCSP presents commentaries on the Murase and Muto \& Mitamura case studies by two Anglo-American commentators, and by two Japanese commentators.

Commenting on Murase's case study is John McLeod of Scotland and Hiroaki Kumano of Japan. Commenting on Muto \& Mitamura's case study is Steven Hayes of the United States and Yoshinobu Kanazawa of Japan. To add to the variety of perspectives in the commentaries, McLeod and Hayes share a theoretical orientation with the cases they comment on, while Kumano and Kanazawa come to the cases they comment on with a different orientation.

\section{REFLECTIONS BY THE ACTION EDITOR ON THE SERIES}

\section{Case Study Methods}

\section{Interventions and Therapeutic Principles}

Before undertaking the comparison of case study methodologies of Muto \& Mitamura (2015) and Murase (2015), it is necessary to elucidate their differing views on what constitutes therapeutic intervention. The goal of Muto and Mitamura's article was to examine the outcome of ACT for depression. Its emphasis is on the implementation of the intervention as prescribed by the treatment manual, with the goal of enhancing treatment integrity and adherence and thus warranting clinical replication. There appears to be a working assumption that what is most effective is the accurate and judicious application of intervention procedures, rather than the therapist as a person who not only conveys the intervention but also builds a therapeutic relationship through interaction with the client. Perhaps it is for this reason that the description of the therapeutic process is carefully controlled to eliminate the subjective experience and internal processes of the therapist, limiting itself to tracing the implementation of specific interventions. Hayes (2015) points out that Acceptance and Commitment Therapy (ACT) is an approach that emphasizes the importance of context. Context in ACT, however, seems to narrowly refer to the context of intervention.

On the other hand, Murase's approach is open-ended and process-oriented in that she adjusts her style of relating to the client according to what she or he needs based on a small number of basic principles. In her approach, which is most similar to a common factors model, basic therapeutic principles are adjusted for each client by the therapist; both the therapist as a person and her clinical judgment play major roles. Therefore, the description of the therapeutic process includes not only observable episodes and events but also the therapist's subjective 
experience and the process of clinical decision-making, as these constitute part of intervention. There is no clear distinction between intervention, therapeutic relationship and therapist stance, which seem seamlessly connected and integrated. The therapist as a person is not a variable distinct from the intervention but an inseparable part of the intervention. In sum, these two case studies reflect fundamental differences in their views of intervention, therapeutic relationship, and therapist engagement.

\section{Case Study Method}

The case study by Muto \& Mitamura (2015) can be characterized as an example of an outcome-oriented case study, as set forth in McLeod's (2010) classification. A number of outcome measures are used to track changes in every session in order to tease out specific interventions and link them to observed changes.

On the other hand, in McLeod classification, Murase's case study is a narrative case study in which the therapist tells the story of therapy from her point of view, inviting readers into the moment-to-moment lived experience of therapy. In addition, a series of drawings were presented which directly and vividly provides viewers with an immediate experience of the drastic changes that occurred in the client. It may be possible to calculate the quantitative reliability of client change in the drawings by having multiple judges rate them according to predetermined criteria. However, that would not seem to make best use of what drawings can communicate and trigger in their viewers. Murase presented follow-up information about the client that she'd heard from the client's sister; this was a general description of the client's adjustment to his life, and it did not examine which interventions were effective in working with Mr. R. In sum, the two articles have quite different conceptualizations of the nature of the effectiveness of psychotherapy.

\section{$\underline{\text { Evidential Role and Educational Role of Case Studies }}$}

Mackrill and Iwakabe (2013) pointed out that case studies have both evidential and educational roles. The evidential role is to demonstrate the effectiveness of a specific intervention and psychotherapy model, whereas the educational role points to the training and educational effect of reading, writing and discussing case studies.

The two articles in this special issue also differed in terms of these two roles. Muto and Mitamura's case study emphasized the evidential role: the case study in and of itself constitutes a piece of evidence for the effectiveness of ACT for depression.

On the other hand, the educational role is more conspicuous in Murase's study. Kumano (2015) and McLeod (2015), who are both seasoned psychotherapists, similarly felt their task as commentators challenged them as therapists and required personal engagement with the case materials. This is akin to the invitation to an experience of deep appreciation that Hayes (2015) described as one role of narrative case studies. McLeod (2015) also referred to the training role of narrative case studies. One of the educational roles of the case study is to generate dialogue comprised of the personal engagement of the therapist and readers, rather than a discussion about the effectiveness of a particular intervention. 
The personal engagement of the therapist indeed has substantial relevance to empirical evidence. In their re-analysis of outcome studies, Kim, Wampold, and Bold (2006), comparing cognitive behavior therapy, interpersonal therapy, and medication for the treatment of depression (Elkin, 1994), demonstrated that while there was no significant difference in the treatment effects of the two psychotherapy interventions, the therapist effect (i.e., the effect of the person of the individual therapist per se; e.g., see Hansen, Lambert, \& Vlass, 2015) occupied 1 to 12\% of the outcome variance. A meta-analysis conducted by McKav, Imei, \& Wampold (2006) indicated that in the pharmacological treatment of depression, the therapist effect is significantly larger than the effect of medication. Based on these findings, Wampold (2012) emphasizes the importance in successful therapy of therapist interpersonal skills, such as interpersonal perception, affective regulation and expressivity, warmth and acceptance, empathy, and focusing on and being responsive to others. Furthermore, reflective practices integral to case study activities - such as the willingness to consider one's own subjective reactions to the client, to exercise critical thinking, and to review one's personal stance towards the client—are all a part of clinical competency. Thus narrative case studies in which the therapist pays attention to the characteristics of a particular client in a specific context, examines his or her own internal process, and engages in open discussion of the case materials with other practitioners are not unscientific relics of the past.

The British Institute of Medicine defines evidence-based medicine as "the integration of best research evidence with clinical expertise and patient values" (Sackett, Straus, Richardson, Rosenberg, \& Haynes, 2000, p. 147). Building on this definition, the APA Presidential Task Force on Evidence-Based Practice describes the purpose of Evidence-Based Practice in Psychology as, "to promote effective psychological practice and enhance public health by applying empirically supported principles of psychological assessment, case formulation, therapeutic relationship, and intervention” (p.273). This definition emphasizes the importance of fitting the therapeutic relationship and interventions to a particular client by the use of assessment and case formulation. To varying degrees, both Muto and Mitamura (2015) and Murase (2015) are well in the range of evidence-based practice in psychology.

In Japan, published narrative case studies are very common. They do not present quantitative outcome measures, and the interventions or the models of therapy are not usually clearly specified. The systematic case study by Muto and Mitamura presents a model of case study that is needed to provide an empirical foundation of psychotherapy in Japan. The incorporation of some of the components of their case study methods is urgently needed. However, integrating descriptions of what happens between the therapist and the client in this objectivist framework should also be a central future task.

On the other hand, Murase's narrative case study recreated the dynamics of the therapy process, allowing its readers to experience the feel of therapy. In order for a therapist to reconstruct the therapeutic process in such a way, as McLeod points out, in addition to having writing and communication abilities, the therapist needs to reflect on his or her own internal processes and to be open to disclosing such processes. This is an integral part of clinical training. However, to date there has been little empirical examination of the educational role of case studies, and such research is very much needed. 
It is important to note that Murase is a highly experienced therapist. If a therapist who is writing a case study is not as experienced, can the case study still engage its readers? Case selection is another issue. The case of Mr. R is unique in many ways. If a therapist chooses less dramatic case materials with slower, smaller changes to be described, how does that affect the learning of readers? We need to study the features and qualities of narrative case studies that make them valuable to the training and education of psychotherapists.

\section{Culture}

The two main articles were a study in contrast in terms of the way they dealt with the issue of culture. Muto (2015) quoted richly from and aligned his position with the novelist Haruki Murakami as he differentiated himself from those authors who emphasize the idea of 'Japaneseness.' However, he also made conscious attempts to blend in 'eastern' or Japanese cultural knowledge and practice by using Chinese characters to explain the meaning of mindfulness and by using a mindfulness exercise modeled after the Japanese tea ceremony. Since the concept of mindfulness in ACT was originally derived from Buddhism, ACT has a strong 'eastern' influence that distinguishes it in part from more rationalist approaches to cognitive therapy. That ACT is one of the more contextual approaches in behavioral therapy is certainly one of the factors associated with the affinity that many Japanese people feel toward it.

Muto (2015) quoted Haruki Murakami’s sentiments toward the notion of Japanese literature as 'high culture' in order to respond to Kanazawa's (2015) comments about the paucity of descriptions of the therapeutic relationship and the emotional interactions between therapist and client. Muto's point was that the emotionality of such aspects is often used to intentionally emphasize the sort of 'Japaneseness' from which he tries to maintain a distance. Instead of emphasizing a grand, overarching 'Japaneseness', Muto, after Murakami, states his preference for examining those cultural elements that still seep out when one has tried to get rid of 'Japaneseness'.

Many of the major figures of Japanese clinical psychology have emphasized the uniqueness of the field as it developed in Japan. Whereas western clinical psychology is based on scientific principles, they argue, Japanese clinical psychology is built on clinical practice as a primary source of knowledge, which led to the conceptualization of the inverted term 'ShinriRinshogaku' instead of the more conventional term for clinical psychology, 'Rinsho-Shinrigaku.' Here, we see a tinge of Nihonjin-ron, or "theories of Japanese uniqueness," the many interdisciplinary components of which are more nationalistic and uncritically accepted than they are academic or objective (Dale, 1987). I share similar doubts and apprehension with Muto in this regard.

In this context, Muto’s effort to maintain objectivity and avoid the idealization or romanticization of a rarefied 'Japaneseness' can be regarded as his attempt to imbue Japanese clinical psychology with new breadth and rigor and to change the institutionalized culture within it that has had such a strong, binding force. However, there is a potential risk in eliminating the intrinsically social, and therefore also cultural, nature of interpersonal and emotional engagements in therapy. Kanazawa's (2015) request for more description of the climate of the 
therapeutic relationship and the nature of the emotional interaction between therapist and client is based on the findings from psychotherapy process-outcome empirical research; it is not just a response to pressure to conform to a Japanese standard of clinical psychology. Here we learn that what is experienced, noted and reported is not simply a matter of culture or of objectivity, but is also informed by an individual, personal decision made by a therapist/author.

On the other hand, a 'Japaneseness' seems to permeate the case study by Murase (2015). Her writing style does not have the formality common to scientific articles. It is written in simple language with some complex theoretical ideas discussed without being too structured. Both verbal and nonverbal exchanges as well as direct and indirect expressions are equally valued. Although exposed to many North American and European therapy models, Murase's integrative approach can be said to be indigenous in that she developed it based on her practice in Japan. On the other hand, as mentioned in Murase's case study, her integrative approach is quite similar to the client-centered/humanistic psychology model of Carl Rogers, the American clinical psychologist, in that it seeks to tap into the client's human potential, with the therapist building an "I-thou" relationship with the client as a person, and with the therapist facilitating the client's expression of feelings.

Murase's case study brings experience that goes beyond the boundaries of Japanese culture. The portraits of historical figures known across time and place, the archetype of the distant or bureaucratic father, and the mother who struggles to maintain the appearance of social presentability while barely keeping it from collapsing from within: a lot more is communicated to readers beyond what is explicitly stated in the case study. Murase is consciously aware of the milieu when she takes an integrative position within the institutionalized culture of Japanese clinical psychology, where different schools are in fierce rivalry with one another. She values a balance between objectivity and empathic alignment and also between different schools of thought. This may be required in her approach, in which the therapist employs a small number of principles to tailor therapy to a particular client.

In sum, culture as represented in these case studies is not only about how people live and experience psychotherapy, but also about how psychotherapists practice therapy in a given cultural context and how they represent what they do. In turn, objectivity is not simply a matter of scientific rigor and the accuracy of one's sensorily-based observations, but it also a political position that one assumes, explicitly or implicitly, within a particular culture.

Finally, I would like to thank the three authors and four commentators for their contributions and for engaging in this dialogue. Although this project required two languages, I was amazed and moved by the accuracy and the depth of understanding that occurred despite the vagaries of translation and transcultural communication. In an era in which evidence-based practice and global mental health issues are of such profound importance to the betterment of human society, I believe that this special issue demonstrates that case studies, case study method, and the discussion of these two topics hold great potential for advancing the understanding of the psychotherapy process and what makes it effective- both within a particular cultural context and across cultures. 
Case Studies in Japan: Two Methods, Two Worldviews, Part 2

S. I wakabe

Pragmatic Case Studies in Psychotherapy, http://pcsp.libraries.rutgers.edu

Volume 11, Module 4, Article 1, pp. 230-238, 12-31-15 [copyright by author]

\section{REFERENCES}

APA Presidential Task Force on Evidence-Based Practice. (2006). Evidence-based practice in psychology. American Psychologist, 61, 271-285.

Dale, P. (1987). Myths of Japanese uniqueness. New York: Routledge.

Elkin, I. (1994). The NIMH Treatment of Depression Collaborative Research Program: Where we began and where we are . In A. E. Bergin, \& S. L. Garfield (Eds.), Handbook of psychotherapy and behavior change (4th ed.). (pp. 114-139). Oxford, England: John Wiley \& Sons.

Hansen, B.P., Lambert. M.J., \& Vlass, E.N. (2015). Sudden Gains and sudden losses in the clients of a "supershrink": 10 case studies. Pragmatic Case Studies in Psychotherapy, 11(3), Article 1, 154-201. Available: http://pcsp.libraries.rutgers.edu

Hayes, S. C. (2015). Examining the ACT model in a case study. Pragmatic Case Studies in Psychotherapy, 11(4), Article 5, 272-278. Available: http://pcsp.libraries.rutgers.edu

Iwakabe, S. (2015). Introduction to case study special issue-- case studies in Japan: Two methods, two worldviews. Pragmatic Case Studies in Psychotherapy, 11 (2), 65-80. Available: http://pcsp.libraries.rutgers.edu

Kanazawa, Y. (2015). The role of context in the case of Taro. Pragmatic Case Studies in Psychotherapy, 11(4), Article 6, 279-284. Available: http://pcsp.libraries.rutgers.edu

Kim, D. M., Wampold, B. E., \& Bolt, D. M. (2006). Therapist effects in psychotherapy: A random effects modeling of the NIMH TDCRP data. Psychotherapy Research, 16, 161172.

Kumano, H. (2015). Discontinuous change facilitated by emotional expression through drawing and the accurate verbal responsiveness of the therapist. Pragmatic Case Studies in Psychotherapy, 11(4), Article 3, 255-263. Available: http://pcsp.libraries.rutgers.edu

Mackrill, T., \& Iwakabe, S. (2013). Making a case for case studies in psychotherapy training: A small step towards establishing an empirical basis for psychotherapy training. Counselling Psychology Quarterly, 26, 3-4, 250-266.

McKay, K. M., Imel, Z. E., \& Wampold, B. E. (2006). Psychiatrist effects in the psychopharmacological treatment of depression. Journal of Affective Disorders, 16, 236242.

McLeod, J. (2010). Case study research in counselling and psychotherapy. London: Sage.

McLeod, J. (2015). Narrative case studies and practice-based learning: Reflections on the case of "Mr. R.” Pragmatic Case Studies in Psychotherapy, 11 (4), Article 2, 239-254. Available: http://pcsp.libraries.rutgers.edu

Murase, K. (2015). The art of communication through drawing: The case of "Mr. R," a young man professing misanthropy while longing for connection with others. Pragmatic Case Studies in Psychotherapy, 11 (2), Article 2, pp. 81-116. Available: http://pcsp.libraries.rutgers.edu

Muto, T. (2015). Acceptance and Commitment Therapy is "Murakami Haruki." Pragmatic Case Studies in Psychotherapy, 11 (4), Article 7, 285-287. Available: http://pcsp.libraries.rutgers.edu 
Case Studies in Japan: Two Methods, Two Worldviews, Part 2

S. I wakabe

Pragmatic Case Studies in Psychotherapy, http://pcsp.libraries.rutgers.edu

Volume 11, Module 4, Article 1, pp. 230-238, 12-31-15 [copyright by author]

Muto, T., \& Mitamura, T. (2015). Acceptance and Commitment Therapy for "Taro," a Japanese client with chronic depression: A replicated treatment-evaluation. Pragmatic Case Studies in Psychotherapy, 11 (2), Article 3, 117-153. Available:

http://pcsp.libraries.rutgers.edu

Sackett, D. L., Straus, S. E., Richardson, W. S., Rosenberg, W., \& Haynes, R. B. (2000). Evidence based medicine: How to practice and teach EBM (2nd ed.). London: Churchill Livingstone. 